\title{
Article \\ Active Coping and Anxiety Symptoms during the COVID-19 Pandemic in Spanish Adults
}

\author{
Raquel Lara 1,2,*(D), Martha Fernández-Daza ${ }^{3,4}$, Sara Zabarain-Cogollo 3,4 , María Angustias Olivencia-Carrión ${ }^{2}$, \\ Manuel Jiménez-Torres ${ }^{2,5}$, María Demelza Olivencia-Carrión ${ }^{6}$, Adelaida Ogallar-Blanco ${ }^{2,5}$ \\ and Débora Godoy-Izquierdo $2,5, *$ (D)
}

check for

updates

Citation: Lara, R.; Fernández-Daza,

M.; Zabarain-Cogollo, S.;

Olivencia-Carrión, M.A.;

Jiménez-Torres, M.;

Olivencia-Carrión, M.D.;

Ogallar-Blanco, A.; Godoy-Izquierdo,

D. Active Coping and Anxiety

Symptoms during the COVID-19

Pandemic in Spanish Adults. Int. J.

Environ. Res. Public Health 2021, 18,

8240. https://doi.org/10.3390/

ijerph18168240

Academic Editors: Benito León del Barco, Damián Iglesias Gallego and Jerónimo González-Bernal

Received: 9 June 2021

Accepted: 29 June 2021

Published: 4 August 2021

Publisher's Note: MDPI stays neutral with regard to jurisdictional claims in published maps and institutional affiliations.

Copyright: (c) 2021 by the authors. Licensee MDPI, Basel, Switzerland. This article is an open access article distributed under the terms and conditions of the Creative Commons Attribution (CC BY) license (https:/ / creativecommons.org/licenses/by/ $4.0 /)$.
1 Departamento Psicología Social, Facultad de Psicología, Universidad de Granada, 18071 Granada, Spain

2 Grupo de Investigación Psicología de la Salud/Medicina Conductual (CTS-267), Universidad de Granada, 18071 Granada, Spain; maolivencia@ugr.es (M.A.O.-C.); mjitor@ugr.es (M.J.-T.); adelaidaogallar@ugr.es (A.O.-B.)

3 Psychology Department, Universidad Cooperativa de Colombia, Santa Marta 110000, Colombia; martha.fernandezd@campusucc.edu.co (M.F.-D.); sara.zabarain@campusucc.edu.co (S.Z.-C.)

4 Grupo de Investigación Estudios Sociales Interdisciplinares-ESI, Santa Marta 110000, Colombia

5 Departamento de Personalidad, Evaluación y Tratamiento Psicológico, Facultad de Psicología, Universidad de Granada, 18071 Granada, Spain

6 Centro de Salud de Torredonjimeno, 23000 Jaén, Spain; dolca80@hotmail.com

* Correspondence: rlaramoreno@ugr.es (R.L.); deborag@ugr.es (D.G.-I.)

\begin{abstract}
The features of the COVID-19 pandemic and the social operations to contain the spread of the virus might have limited or altered coping, including healthy habits such as exercise, this contributing to a myriad of negative consequences for the mental health of the global population. We explored the contribution of coping and physical activity to the management of anxiety in Spanish adults during an active phase of the epidemic, as well as the relationship between these strategies. A total of 200 young and adult individuals (70\% women) voluntarily completed an anxiety inventory, a coping skills self-report and a personal data section including exercise practice. The participants reported in average a mild yet existing level of anxiety symptoms; a third reported noticeable symptoms. At the time of the study, the participants used more adaptive than maladaptive coping styles. Participants' anxiety was inversely correlated with an active coping style, and positively with an avoidant style; physical activity correlated positively with an active coping style, and regular exercisers used more frequently active coping. Controlling for confounders, active coping, avoidant coping and exercise during the pandemic predicted anxiety symptoms. Other findings indicated that exercise was used as a coping strategy for dealing with emotional distress. Our results highlight the positive impact of functional coping and exercise for the management of negative states such as anxiety during the pandemic, and underline the importance of developing interventions aimed at enhancing coping skills for promoting physical and mental well-being of the population during health and social crises.
\end{abstract}

Keywords: anxiety; coping; exercise; COVID-19; mental health

\section{Introduction}

The World Health Organization (WHO) declared on 12 March 2020 that the new 2019 coronavirus (SARS-CoV-2) and its related syndrome (COVID-19) constituted an official pandemic due to the 125,000 cases detected in 118 countries at that moment [1]. The COVID19 pandemic has spread rapidly worldwide and, given the absence of effective vaccines until very recently, strict controlling measures (e.g., quarantines; movement restrictions, stopping mass gathering and social isolation; risk-reducing personal actions) differing in duration and severity have been the only possible interventions to protect peoples' health. Despite the fact that the effectiveness of these procedures has been well established $[2,3]$, 
their outcomes in terms of mental health are still unclear. Several investigations [2-7] and reviews of previous outbreaks [8,9] stress the consequences of the recent COVID19 outbreak and related quarantine actions in terms of a variety of psychopathological manifestations.

Fear of infection, social distancing and separation from loved ones, loss of freedom, prohibition of common activities (e.g., exercise-sporting activities) and the closure of recreational facilities (parks, gyms, cinemas, theaters) can make coping quite complicated. In addition, other difficulties such as changes in daily life, economic and job problems or, on the contrary, exigent demands in terms of work overload and family conciliation, could also challenge the adoption of coping strategies [2,4,10]. Emotional distress (e.g., sadness, worry, loneliness, stress, hypervigilance, insomnia) should be considered a normal way in which people react to uncertain and dangerous situations, as a global pandemic. Nevertheless, an increased incidence of psychopathological disorders (e.g., stress, anxiety, depression, post-traumatic stress) has been documented in several systematic reviews [3,4,11-14] and meta-analysis $[15,16]$. Specifically, a study [17] found that, of all participants in the reviewed studies, $20.8 \%$ had clinically meaningful levels of psychological distress, $22.7 \%$ of depressive symptoms, $21.7 \%$ of post-traumatic stress and $16.2 \%$ of anxiety symptoms during and after quarantine periods. In addition, it has been shown that the first weeks after the pandemic started in China there was an increase in negative emotions (anxiety and depression) but also a decrease in life satisfaction [18].

Research has also supported that the adverse effects of COVID-19 pandemic in terms of psychological distress are largely derived from dysfunctional cognitive, behavioral and emotional coping efforts $[19,20]$. Behavioral, cognitive and emotional coping strategies have been found to be helpful for dealing with negative experiences, since they reduce the burden imposed by prolonged distress, enable cognitive resources to deal with everyday stressors and allow adaptation to environmental changing and demanding situations during pandemics and natural disasters [21,22]. Furthermore, coping has been demonstrated to be a key factor for psychological well-being and mental health issues during the COVID19 era, with problem-focused coping strategies, cognitive reappraisal, social support and avoidant coping strategies along with other coping resources such as meaning in life and social connectedness as the most commonly used coping strategies $[19,20,23-30]$. A review [31] has found that all the guidelines for coping with mental problems derived from COVID-19 included tips for maintaining good mental health, descriptions of a variety of psychological skills to help people cope with their anxiety and worries and the promotion of interpersonal connection at home to generate social support. Nevertheless, the role of coping for emotional distress during this crisis has been scarcely investigated.

On the other hand, the imposed restrictions during the different quarantine periods have limited people's physical activities, which has led to an increase in sedentary lifestyle in the population [32-35]. All but one of the studies included in a review [35] reported a decrease in the volume of physical activity during or after COVID-19-related confinements compared to pre-pandemic levels. These data are congruent with other investigations [36-41] reporting that more than $50 \%$ of the examined population decreased their exercise practice during confinement.

This reduction in exercise has a deleterious effect on physical, mental and social health $[32,42-47]$. The decrease in physical activity is associated with higher negative affect and anxiety and lower levels of energy [48-50] as well as to the worsening of other health-related behaviors (e.g., diet, tobacco and alcohol consumption, sleep behaviours) during confinement $[46,51]$. On the contrary, staying active or becoming active during the pandemic reduces the risk of depression and anxiety, predicts recovery experiences and improves emotional well-being and life satisfaction [52-58]. Consequently, physical activity is considered a protective factor $[59,60]$. Several reviews support the relationship between exercise during the COVID-19 pandemic and better mental health [61-63]. The practice of exercise along with spending time with family, talking with friends, healthy eating, sleep hygiene and investing time in pleasant hobbies have been considered successful strategies 
for coping with mental distress during COVID-19, these practices being associated with better psychological health [64-68]. This has led some researchers to consider the practice of physical activity as a coping strategy itself [69].

The WHO [1] has recognized the importance of paying attention to the mental health of the general population during the COVID-19 pandemic. Understanding how effective coping strategies during the pandemic operate is important, not only to gain knowledge on their health outcomes but also to help developing public health interventions in specific populations, such as the promotion of functional coping strategies for restrictive quarantine situations [70].

Therefore, the main aim of this study was to examine anxiety manifestations and coping strategies adopted to manage anxiety, including the practice of physical activity, during an active stage of the COVID-19 pandemic in Spain (December 2020-February 2021, which corresponded to the period between the ending of the second wave and the beginning and peak of the third wave of the pandemic in this nation, according to the Ministry of Health of the Government of Spain) in adults of both sexes with different personal and sociodemographic characteristics. We hypothesized that anxiety symptoms would be noticeable (hypothesis 1 ) and also that the management of anxiety would be executed through both functional and dysfunctional coping (hypothesis 2). We also hypothesized that levels of physical activity would be lower compared to periods before the beginning of the pandemic (hypothesis 3), as well as that it would be a positive resource for anxiety management (hypothesis 4).

In addition, the present study also has the following specific objectives: (1) To determine if specific coping strategies and styles are associated with different anxiety levels. We expected to find that functional coping skills would be associated with lower anxiety, and that more dysfunctional coping would be associated with increased anxiety (specific hypothesis 2.1). We also expected that exercise practice would be linked to the use of other functional coping skills (specific hypothesis 4.1) and to decreased anxiety manifestations (specific hypothesis 4.2). (2) To determine whether participants with different levels of physical activity during the COVID-19 pandemic show differences in their efforts for coping with mental distress. We hypothesized that those participants who regularly practiced exercise would use more functional coping styles, and that non-practitioners would endorse more dysfunctional coping styles (specific hypothesis 4.3). (3) To explore the impact of coping styles and levels of physical activity on the participants' anxiety manifestations. We hypothesized that more functional coping styles would predict lower anxiety symptoms, compared to dysfunctional styles (specific hypothesis 2.2); furthermore, exercise would also have a positive impact on anxiety reducing symptoms of emotional distress (specific hypothesis 4.4).

\section{Materials and Methods}

\subsection{Participants}

Two hundred Spanish individuals of both sexes (70\% women) with ages between 18 and 74 years and different personal and sociodemographic conditions (Table 1) voluntarily participated in this study. This was a non-probabilistic convenience sample. The sample size was estimated prior to the study using the Clinical and Translational Science Institute (University of California, San Francisco, CA, USA) online calculator for clinical correlational research [71] in 194 participants for an $\alpha$ of 0.05 , a $\beta$ of 0.02 , and expected $r$ s for associations among the study variables previously reported (e.g., $r$ coping-mental health indicators $\approx$ $0.20[20])$.

Of them, $8 \%$ had shown symptoms of COVID-19 or were diagnosed as positive for infection at the time of the study (December 2020-February 2021). According to the Ministry of Health of the Government of Spain, it is estimated that in 1 March 2021, about 3,204,531 out of 47,351,567 Spanish individuals had been diagnosed with COVID-19, corresponding to a $6.7 \%$ of the population; thus, the percentage of participants in the present study affected by the infection fits the national proportions of the pandemic for that moment. On the 
other hand, $86.5 \%$ reported being sedentary on a regular basis at the time of the pandemic, compared to $20.5 \%$ reporting being sedentary before the pandemic.

Table 1. Sociodemographic data from the participants.

\begin{tabular}{|c|c|c|c|}
\hline \multicolumn{2}{|c|}{ Conditions } & \multirow{2}{*}{\begin{tabular}{c|}
$N$ \\
140
\end{tabular}} & \multirow{2}{*}{$\begin{array}{l}\% \\
70\end{array}$} \\
\hline & Women & & \\
\hline Sex & Men & 60 & 30 \\
\hline \multirow{2}{*}{ Age range } & Young adulthood: $18-44$ yr. & 170 & 85 \\
\hline & Middle and older adulthood: $45-74$ yr. & 30 & 15 \\
\hline \multirow{4}{*}{ Marital status } & In a relationship/Married & 32 & 16 \\
\hline & Single & 136 & 68 \\
\hline & Separated/Divorced/Widow-er & 32 & 16 \\
\hline & Primary school & 5 & 2.5 \\
\hline \multirow{4}{*}{ Education level } & High School & 22 & 11 \\
\hline & University (current) & 58 & 29 \\
\hline & University (finished) & 94 & 47 \\
\hline & Postgraduate studies & 21 & 10.5 \\
\hline \multirow{4}{*}{ Employment situation } & Employed & 61 & 30.5 \\
\hline & Studying & 131 & 65.5 \\
\hline & Unemployed, including housework & 6 & 3 \\
\hline & Retired, pensioner & 2 & 1 \\
\hline \multirow{4}{*}{ COVID-19 } & Without symptoms/negative diagnosis & 184 & 92 \\
\hline & Symptomatic but not diagnosed & 4 & 2 \\
\hline & Positive diagnosis & 12 & 6 \\
\hline & $0-1$ & 20 & 10 \\
\hline \multirow{3}{*}{ Number of cohabitants } & $2-3$ & 131 & 65.5 \\
\hline & 4 or more & 49 & 24.5 \\
\hline & 0 & 165 & 82.5 \\
\hline \multirow[t]{3}{*}{ Number of children } & $1-2$ & 28 & 14 \\
\hline & 3 or more & 7 & 3.5 \\
\hline & Sedentary & 41 & 20.5 \\
\hline \multirow[t]{2}{*}{ Pre-pandemic physical activity } & Mild activity & 44 & 22 \\
\hline & Active & 115 & 57.5 \\
\hline \multirow{3}{*}{$\begin{array}{l}\text { Physical activity during the } \\
\text { pandemic }\end{array}$} & Sedentary & 173 & 86.5 \\
\hline & Mild activity & 5 & 2.5 \\
\hline & Active & 22 & 11 \\
\hline
\end{tabular}

\subsection{Measures}

The following measures were used:

- Zung's Self-Reported Anxiety Scale (SAS), Spanish version [72]. The SAS is a 20-item self-report measure designed to assess levels of psychological ("I feel scared for no reason", "I feel like I'm falling and breaking apart") and somatic ("My arms and legs are shaking", "I feel my heart beating fast") symptoms of anxiety through four types of manifestations during the last week: cognitive, autonomic, motor and central nervous system symptoms. Each item is scored on a Likert-type scale from 1 (never) to 4 (most of the time). Some questions are worded negatively to avoid response bias. Total raw scores range from 20 to 80 points. This raw score is converted to an "Anxiety Index" using a provided conversion table. According to this Anxiety Index, four levels of anxiety are differentiated: absence of anxiety (20-44 points), mild anxiety (45-59 points), moderate/severe anxiety (60-74 points) and extreme anxiety ( $\geq 75$ points). The SAS has well-established psychometric properties $[73,74]$ and has been widely used, also in studies conducted during the COVID-19 pandemic [75,76]. The Spanish validation studies of the SAS reported a Cronbach's $\alpha$ value of 0.88 [77]. In the present study, $\alpha$ was 0.84 .

- Scale of Styles and Coping Strategies $E^{3} A$ [78]. This 72-item self-report evaluates 18 coping strategies (with four items for each one of the strategies): positive reappraisal, depressive reaction, denial, planning, acceptance, cognitive disconnection, personal development, emotional concealment, emotional distancing, suppression of distracting activities, 
coping restrainment, coping suppression, problem solving, social support for problem solving, behavioral disconnection, emotional collapsed in each of the three categories of styles; the interpretation of each of the coping expression, emotional social support and palliative response; and eight different coping styles, based on the methods, focus and type of activity used: active, passive and avoidant coping; response-, problem- and emotionfocused coping; and behavioral and cognitive coping (see Figure 1). Each item is rated using a Likert-type scale from 0 (never) to 3 (always). The inventory correction procedure has two phases: correction of coping strategies and correction of coping styles. First, the 18 coping strategies are scored; the higher the score obtained, the more commonly that coping strategy is used. Secondly, coping styles are scored by adding the scores obtained in the corresponding coping strategies, noting that each strategy in styles is the same as that of the coping strategies. The authors reported a Cronbach's $\alpha$ of 0.73 for the complete scale, with subdimensions' and styles' $\alpha$ up to 0.73 and 0.83 , respectively [79]. In the present study, $\alpha$ was 0.90 .

Coping Strategies

Adaptive/Helpful Coping
1. Positive reappraisal: Creating a new meaning of the situation
making something good out of the problem

4. Planning: Efforts for changing the situation based on an analytical, rational and experiential approach to the problem

5. Acceptance: Acceptance of lack of personal control over the situation and acquiescence to its consequences, tolerating having unmanageable problems

7. Personal development: Considering the problem as a stimulus and an opportunity for learning and personal growth

10. Suppression of distracting activities: Efforts to stop activities that detract from focusing in understanding and solving the problem

11. Coping restrainment: Curtail and postponement of any management effort until complete information on the problem is obtained

13. Problem solving: Deciding and performing a reasoned and direct action to manage the problem

14. Social support for problem solving: Seeking information, counseling or help from others to resolve the problem

16. Emotional expression: Expressing to others one's own emotional reactions generated by the situation
Maladaptive/Unhelpful Coping

2. Depressive reaction: Feeling overwhelmed by the situation, unconfident in oneself and pessimistic about the outcomes of the problem

3. Denial: Lack of acceptance and avoiding the reality by distorting or defacing the problem

6. Cognitive disconnection: Using distracting thinking to avoid focusing on the problem

8. Emotional concealment: Efforts for covering up personal emotions to others

9. Emotional distancing: Cognitive efforts for suppressing the emotional outcomes generated by the situation

12. Coping suppression: Stopping courses of action fearing that any effort can make things worse o estimating the problem as unsolvable

15. Behavioral disconnection: Avoidance of any response or action for solving the problem

17. Emotional social support: Seeking sympathy and solace in other people for one's own emotions

18. Palliative response: Avoiding the problem by maladaptive actions performed in an attempt to feel better (e.g., alcohol)

Figure 1. Cont. 


\section{Coping Styles}

[Strategies Encompassed in each Style]

\section{Method}

Active coping [1, 4, 7, 10, 13 \& 16]

Passive coping $[2,5,8,11,14 \& 17]$

Avoidant coping $[3,6,9,12,15$ \& 18]

Focus

Response-focused coping [1, 2, 3, 10, $11 \& 12]$

Problem-focused coping [4, 5, 6, 13, $14 \& 15]$

Emotion-focused coping [7, 8, 9, 16, 17 \& 18]

Activity

Cognitive coping [1, 2, 3, 4, 5, 6, 7, 8 \& 9]

Behavioral coping [10, 11, 12, 13, 14, 15, 16, 17 \& 18]

Figure 1. Coping strategies and styles.

In addition, participants answered questions about their sociodemographic and personal data (age, sex/gender, marital status, educational level, employment status, number of children, number of cohabitants). They also self-reported their level of physical activity before and during the pandemic on a weekly-time spent, on a scale where $0=$ nothing, 1 $=30 \mathrm{~min} /$ week as much, $2=1 \mathrm{~h} /$ week as much and $3=2 \mathrm{~h}$ or more $/$ week. We decided to use a global "duration" index, instead of other indicators (e.g., intensity, frequency) given that these other features of practice might be limited by the imposed restrictions. This decision is based on the fact that even moderate levels of physical activity are related to anxiety reductions [80]. Based on their responses, the participants were classified as sedentary (response 0 ), mildly active (responses 1 and 2 ) and sufficiently active (response 3). Finally, they indicated if they had had symptoms of COVID-19, whether or not they had been diagnosed with COVID-19 by means of a positive test, or if they had not had symptoms or a diagnosis of the disease.

\subsection{Procedure}

Both the recruitment of participants and the administration of the measures were carried out online. First, we presented the study to the community and requested collaboration through different social resources (e.g., Facebook, Whatsapp, Instagram, email) intending to reach a wide and heterogeneous sample. People who decided to collaborate were directed to an online survey carried out through Google Forms where detailed information about the study, its aims and the rights of the participants were presented. They then confirmed a consent blank and received specific instructions on how to complete the measurements before starting the survey. All measurements were completed in a single application by the participants. Finally, the database was downloaded and checked. Participants not meeting inclusion criteria (i.e., being 18 yr. or older, Spanish nationality or residence $>1$ year, reading and writing Spanish fluently, voluntary participation) or with exclusion criteria (i.e., severe physical or mental health issues) were removed from the analyses. Given that all questions in the survey were mandatory, there were no participants with missing or incomplete data who were removed from the analyses.

\subsection{Study Design and Data Analyses}

This is a correlational cross-sectional study. Preliminary and exploratory analyses of the data were conducted to ensure the adequacy of the input and to check missing data or outliers, as well as to verify parametric assumptions. Although the normality test indicated that most of the variables did not fit a normal distribution (Kolmogorov- 
Smirnov's test, $p<0.05)$, the Levene's test confirmed the homogeneity of the variances for most variables $(p>0.05)$, and thus we performed parametric tests for the statistical analyses. Besides descriptive analyses, we conducted Pearson's $r$ correlations, Student's $t$ tests, one-way ANOVA and post hoc comparisons (Bonferroni's or Games-Howell's tests, when appropriate) and hierarchical multiple linear regressions. The significance level for all tests was established at $p<0.05$.

\section{Results}

Table 2 shows the descriptive results for participants' anxiety symptoms and coping strategies and styles. The mean (raw) level of anxiety at the time of the study was 42.4 $(S D=9.5)$. According to the Anxiety Index, participants were classified into the categories of: absence of anxiety $(n=122,61 \%)$, mild anxiety $(n=65,32.5 \%)$ and moderate-severe anxiety $(n=13,6.5 \%)$; none of the participants was classified as having extreme anxiety. In addition, of the 18 coping strategies assessed, the most used were: Personal development, Acceptance, Positive reappraisal, Problem solving, Planning and Emotional social support. Among the coping styles, the most used was the Active method.

Table 2. Descriptive data and correlations between anxiety, coping strategies and styles and physical activity.

\begin{tabular}{|c|c|c|c|c|}
\hline Variables (Possible Range of Scores) & $M$ & $S D$ & Anxiety $r$ & Exercise $r$ \\
\hline Anxiety (20-80) & 42.43 & 9.52 & - & 0.07 \\
\hline \multicolumn{5}{|l|}{ Coping strategies $(0-12)$ : } \\
\hline 1. Positive reappraisal & 6.19 & 2.57 & $-0.29 * *$ & 0.10 \\
\hline 2. Depressive reaction & 4.81 & 2.01 & 0.07 & -0.07 \\
\hline 3. Denial & 2.83 & 2.08 & $0.17 *$ & -0.09 \\
\hline 4. Planning & 6.07 & 2.40 & -0.10 & $0.18 * *$ \\
\hline 5. Acceptance & 6.20 & 2.12 & $-0.23^{* *}$ & 0.14 \\
\hline 6. Cognitive disconnection & 4.84 & 2.35 & $0.15 *$ & -0.06 \\
\hline 7. Personal development & 7.56 & 2.53 & $-0.20 * *$ & $0.17 * *$ \\
\hline 8. Emotional concealment & 5.15 & 2.50 & 0.08 & 0.02 \\
\hline 9. Emotional distancing & 4.52 & 1.83 & $0.18 *$ & 0.04 \\
\hline 10. Suppression of distracting activities & 4.18 & 1.92 & -0.05 & -0.02 \\
\hline 11. Coping restrainment & 5.37 & 2.20 & 0.01 & 0.06 \\
\hline 12. Coping suppression & 3.96 & 2.02 & -0.03 & -0.08 \\
\hline 13. Problem solving & 6.15 & 2.37 & $-0.18 *$ & $0.16 *$ \\
\hline 14. Social support for problem solving & 3.14 & 2.10 & $0.16 *$ & -0.01 \\
\hline 15. Behavioral disconnection & 3.30 & 1.85 & 0.05 & -0.10 \\
\hline 16. Emotional expression & 5.76 & 2.38 & 0.08 & 0.12 \\
\hline 17. Emotional social support & 5.98 & 2.81 & 0.02 & 0.11 \\
\hline 18. Palliative response & 2.54 & 2.10 & $0.29 * *$ & -0.07 \\
\hline \multicolumn{5}{|l|}{ Coping styles: } \\
\hline Active method (0-72) & 35.91 & 10.32 & $-0.18 *$ & $0.17 *$ \\
\hline Passive method (0-72) & 30.65 & 7.82 & -0.03 & 0.08 \\
\hline Avoidant method (0-72) & 21.97 & 8.53 & $0.20 * *$ & -0.09 \\
\hline Response-focused (0-72) & 27.34 & 7.71 & -0.05 & 0.02 \\
\hline Problem-focused (0-72) & 29.69 & 7.66 & -0.05 & 0.10 \\
\hline Emotion-focused (0-72) & 31.51 & 7.80 & 0.11 & 0.13 \\
\hline Behavioral activity (0-108) & 48.16 & 11.40 & -0.05 & 0.09 \\
\hline Cognitive activity (0-108) & 40.38 & 11.09 & 0.06 & 0.05 \\
\hline
\end{tabular}

In addition, Table 2 shows the significant correlations among anxiety, coping strategies and styles and exercise practice (during the study). Participants' anxiety inversely correlated with four of the 18 coping strategies, namely Positive reappraisal, Acceptance, Personal development and Problem solving and one of the eight coping styles, i.e., Active coping; it was positively associated with five strategies, namely Denial, Cognitive discon- 
nection, Emotional distancing, Social support for problem solving and Palliative response and one coping style, i.e., Avoidant coping. In turn, exercise practice was positively associated with the use of three coping strategies, namely Planning, Personal development and Problem solving and one coping style, i.e., Active coping. The zero-order association between anxiety symptoms and physical activity was non-significant $(p=0.349)$.

Table 3 shows means and standard deviations for the 18 coping strategies and eight coping styles evaluated by levels of physical activity practice. According to their global scores, the participants were classified into three levels of exercise practice during the pandemic: sedentary (SA) $(n=173,86.5 \%)$, slightly active (LA) $(n=5,2.5 \%)$ and active (AA) $(n=22,11 \%)$. These three subgroups reported significantly different levels of practice ( $F=3735.491, p<0.001)$, with significant differences for coping style, i.e., Active method, and four of the 18 coping strategies (Planning, Acceptance each pair comparison. When we compared the coping strategies and styles by exercise level, we decided to include in the mean comparison analyses only the SA and AA subgroups due to the limited size of the LA subgroup. We found significant differences between the SA and AA groups in several coping endpoints. In particular, we found significant differences for one, Personal development and Problem solving). In all cases, active participants scored higher than their sedentary counterparts (see Table 3 and Figure 2).

Table 3. Descriptive findings and mean comparisons (Student's $t$ tests) for the coping strategies and styles by physical activity.

\begin{tabular}{|c|c|c|c|c|c|c|c|}
\hline \multirow{2}{*}{ VARIABLES (Min-Max) } & \multicolumn{2}{|c|}{ SA $(86.5 \%)$} & \multicolumn{2}{|c|}{ LA $(2.5 \%)$} & \multicolumn{2}{|c|}{ AA (11\%) } & \multirow{2}{*}{$\begin{array}{c}\text { SA vs. AA } \\
t(p)\end{array}$} \\
\hline & $M$ & $S D$ & $M$ & $S D$ & $M$ & $S D$ & \\
\hline Positive reappraisal (0-12) & 6.11 & 2.59 & 6.00 & 3.46 & 6.91 & 2.25 & $-1.382(0.169)$ \\
\hline Depressive reaction (0-12) & 4.86 & 2.04 & 4.80 & 1.64 & 4.41 & 1.89 & $0.974(0.331)$ \\
\hline Denial $(0-12)$ & 2.90 & 2.08 & 3.00 & 2.12 & 2.27 & 2.10 & $1.323(0.188)$ \\
\hline Planning $(0-12)$ & 5.90 & 2.35 & 6.60 & 2.79 & 7.27 & 2.45 & $-2.561\left(0.011^{*}\right)$ \\
\hline Acceptance (0-12) & 6.12 & 2.08 & 4.60 & 2.30 & 7.23 & 2.02 & $-2.366(0.019 *)$ \\
\hline Cognitive disconnection $(0-12)$ & 4.90 & 2.22 & 4.40 & 1.52 & 4.45 & 3.36 & $0.823(0.412)$ \\
\hline Personal development (0-12) & 7.42 & 2.48 & 6.60 & 2.19 & 8.91 & 2.60 & $-2.633(0.009 *)$ \\
\hline Emotional concealment (0-12) & 5.13 & 2.54 & 4.60 & 1.67 & 5.36 & 2.36 & $-0.405(0.686)$ \\
\hline Emotional distancing (0-12) & 4.48 & 1.92 & 5.60 & 0.55 & 4.59 & 1.14 & $-0.266(0.791)$ \\
\hline Suppression of distracting activities (0-12) & 4.20 & 1.92 & 3.00 & 1.73 & 4.23 & 2.00 & $-0.057(0.954)$ \\
\hline Coping restrainment $(0-12)$ & 5.34 & 2.16 & 4.40 & 2.19 & 5.86 & 2.51 & $-1.050(0.295)$ \\
\hline Coping suppression (0-12) & 4.03 & 2.08 & 3.20 & 0.45 & 3.59 & 1.71 & $0.947(0.345)$ \\
\hline Problem solving $(0-12)$ & 6.01 & 2.39 & 6.00 & 2.83 & 7.27 & 1.83 & $-2.388\left(0.018^{*}\right)$ \\
\hline Social support for problem solving (0-12) & 3.15 & 2.08 & 3.40 & 3.29 & 3.05 & 2.01 & $0.223(0.824)$ \\
\hline Behavioral disconnection (0-12) & 3.36 & 1.82 & 3.80 & 2.17 & 2.68 & 1.94 & $1.631(0.105)$ \\
\hline Emotional expression (0-12) & 5.64 & 2.37 & 6.60 & 4.16 & 6.50 & 1.92 & $-1.633(0.104)$ \\
\hline Emotional social support (0-12) & 5.87 & 2.76 & 6.60 & 3.72 & 6.77 & 2.98 & $-1.435(0.153)$ \\
\hline Palliative response $(0-12)$ & 2.57 & 2.06 & 3.60 & 2.19 & 2.00 & 2.35 & $1.207(0.229)$ \\
\hline Active method (0-72) & 35.29 & 10.19 & 34.80 & 15.58 & 41.09 & 8.97 & $-2.546(0.012 *)$ \\
\hline Passive method (0-72) & 30.46 & 7.83 & 28.40 & 8.14 & 32.68 & 7.66 & $-1.256(0.211)$ \\
\hline Avoidant method (0-72) & 22.23 & 8.44 & 23.60 & 5.32 & 19.59 & 9.71 & $1.359(0.176)$ \\
\hline Response-focused (0-72) & 27.43 & 7.90 & 24.40 & 3.91 & 27.27 & 6.77 & $0.091(0.927)$ \\
\hline Problem-focused (0-72) & 29.43 & 7.47 & 28.80 & 9.83 & 31.95 & 8.61 & $-1.464(0.145)$ \\
\hline Emotion-focused (0-72) & 31.12 & 7.88 & 33.60 & 7.30 & 34.14 & 6.95 & $-1.715(0.088)$ \\
\hline Behavioral activity (0-108) & 47.81 & 11.54 & 46.20 & 7.66 & 51.41 & 10.83 & $-1.388(0.167)$ \\
\hline Cognitive activity (0-108) & 40.17 & 11.03 & 40.60 & 12.01 & 41.95 & 11.77 & $-0.708(0.480)$ \\
\hline
\end{tabular}



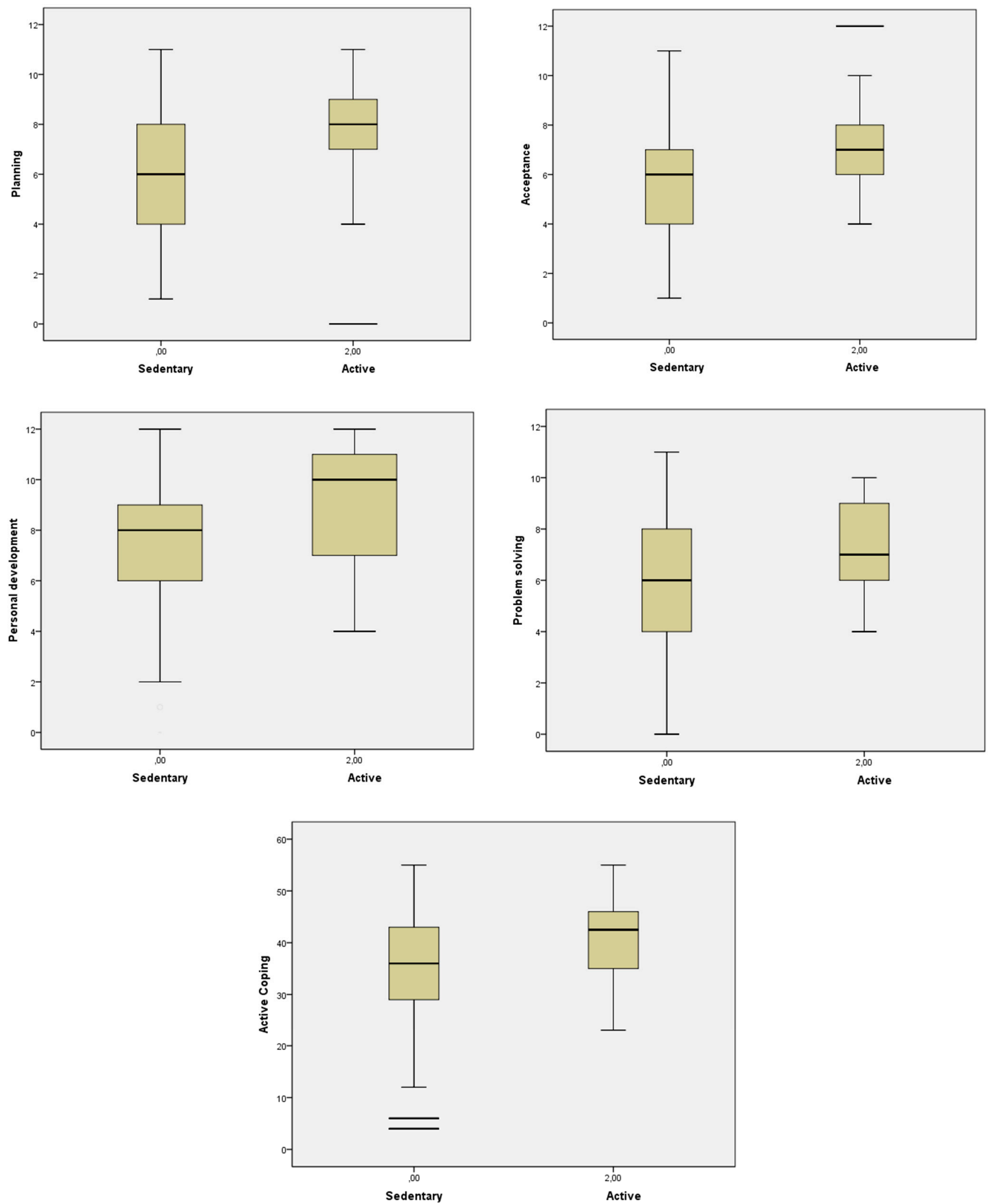

Figure 2. Comparisons of coping strategies between the different levels of physical exercise practice: SA (sedentary) vs. AA (active).

Finally, we performed a hierarchical multiple linear regression analysis to determine the impact of coping styles and exercise during the pandemic on anxiety manifestations, 
controlling for educational level and pre-pandemic level of exercise. Sex-gender and age were introduced in a first analysis, but both were non-significant predictors and were omitted in further analyses to increase the statistical power of the test. The other sociodemographic variables were not included in the analysis due to the lack of representativeness of some of their levels. We found that only the Active method, the Avoidant method and exercise during the pandemic predicted participants' anxiety manifestations (Table 4). For every 1 unit increase in these indicators, anxiety decreased 0.3 standard units (active method) or increased 0.2 standard units (avoidant method). Exercise positively predicted anxiety level $(\beta=0.15)$, which might point to that exercise is being used as a management strategy itself when the individual desires to deal with emotional distress. To test this new hypothesis, a similar hierarchical multiple linear regression analysis was conducted regressing exercise level based on coping styles and distress symptoms, controlling for prepandemic practice and education level (the same decisions on sociodemographic variables than for the previous analysis were adopted for the present one). Regular exercise habit, anxiety levels and Active coping style significantly predicted exercise levels. A 1-point increase in the predictors was associated with increases in exercise practice of 0.15 to 0.20 SD. Yet a marginally significant finding, Avoidant coping inversely predicted exercise (Table 4).

Table 4. Significant predictors of anxiety considering active, passive and avoidant coping styles and the level of exercise during the pandemic (upper panel) and of exercise practice considering active, passive and avoidant coping styles and anxiety (lower panel) (with covariates, final models).

\begin{tabular}{|c|c|c|c|c|c|}
\hline Variable & & Predictor & Cor. $R^{2}$ & Stand. $\beta$ & $t(p)$ \\
\hline \multirow{3}{*}{$\begin{array}{c}\text { Anxiety } \\
(F=4.103, p<00.01)\end{array}$} & Step 1 & $\begin{array}{c}\text { Education level } \\
\text { Pre-pandemic exercise level }\end{array}$ & 0.002 & $\begin{array}{c}0.07 \\
-0.07\end{array}$ & $\begin{array}{c}0.937(0.350) \\
-1.010(0.314)\end{array}$ \\
\hline & Step 2 & $\begin{array}{l}\text { Active coping style } \\
\text { Passive coping style } \\
\text { Avoidant coping style }\end{array}$ & 0.070 & $\begin{array}{c}-0.31 \\
0.13 \\
0.20\end{array}$ & $\begin{array}{c}-3.255\left(0.001^{* *}\right) \\
1.254(0.211) \\
2.511\left(0.013^{* *}\right)\end{array}$ \\
\hline & Step 3 & Current exercise level & 0.086 & 0.15 & $2.072(0.040 *)$ \\
\hline \multirow{3}{*}{$\begin{array}{l}\text { Exercise during pandemic } \\
\qquad(F=2.930, p<0.05)\end{array}$} & Step 1 & $\begin{array}{c}\text { Education level } \\
\text { Pre-pandemic exercise level }\end{array}$ & 0.016 & $\begin{array}{c}-0.09 \\
0.14\end{array}$ & $\begin{array}{l}-1.239(0.217) \\
1.972(0.050+)\end{array}$ \\
\hline & Step 2 & Anxiety & 0.019 & 0.15 & $2.072(0.040 *)$ \\
\hline & Step 3 & $\begin{array}{l}\text { Active coping style } \\
\text { Passive coping style } \\
\text { Avoidant coping style }\end{array}$ & 0.055 & $\begin{array}{c}0.20 \\
0.02 \\
-0.16\end{array}$ & $\begin{array}{c}2.030(0.044 *) \\
0.160(0.873) \\
-1.938(0.054 \dagger)\end{array}$ \\
\hline
\end{tabular}

** $p<0.01 ; * p<0.05 ;+p<0.10$.

\section{Discussion}

The main objective of this study was to examine the current manifestations of anxiety and the coping strategies executed to manage emotional distress during an active stage of the COVID-19 pandemic in Spain in a group of adults of both genders with different sociodemographic and personal characteristics. Contrary to expectations (hypothesis 1 ), we found that average anxiety levels were 42 over 80 , bordering on a mild anxiety problem. This might be due to the fact that an active method focused on managing the problem and dealing with emotional reactions was the most used coping style to handle the situation; and the coping strategies most used were more functional (e.g., personal development, positive reappraisal, planning, problem solving, acceptance) rather than dysfunctional ones (e.g., depressive reaction). Thus, all these coping resources might be helping individuals to successfully manage their emotional status. However, when dividing the sample by the anxiety index, it clearly appears that $32.5 \%$ have mild anxiety symptoms and $6.5 \%$ have moderate or severe anxiety symptoms, which means that more than $1 / 3$ of the participants were suffering anxious symptomatology of noticeable intensity. Our results are in line 
with previous reviews and meta-analyses in which anxiety is considered an important consequence of living under the COVID-19 outbreak [3,4,11-16]. In addition, all these findings point to the importance of providing the community with the necessary coping skills for managing emotional distress. Thus, national and supranational organisms taking care of people's health have the responsibility of developing widespread interventions focused on increasing the individuals' and the communities' resources for maintaining the mental health of worldwide citizens.

As we have emphasized, on average, the coping strategies and styles most used are mainly functional (hypothesis 2). However, the obtained scores for these skills are still moderate, and some other functional strategies that could be also helpful for the management of anxiety symptoms have not been profusely used (e.g., social support for problem solving, suppression of distracting activities). The strategies used by the participants are similar to the strategies found in previous research where the importance of behavioral and emotional coping is highlighted, since they have turned out to be the most beneficial [19-21,28]. Nonetheless, the creation of intervention programs aimed at training the most effective and helpful coping strategies would be advisable in order to improve people's success when putting them into practice to deal with the emotional burden of a major life stressor such as a pandemic.

In this sense, physical activity can be viewed as a coping resource. Regarding active behavior, we found that the prevalence of a sedentary lifestyle is four times higher during the pandemic than in the pre-pandemic stage (21\% pre-pandemic, $87 \%$ during the pandemic) (hypothesis 3). This worrying withdrawal during the pandemic is similar to that found by other authors [32-41]. The negative change respecting physical activity is due surely to the restrictions to prevent the virus spread (e.g., confinement, locking of outdoor and indoor facilities, social distancing), but also undoubtedly to motivational factors: practice in these conditions might be considered less fun or enjoyable, the lacking of appropriate home spaces or resources such as home-guided programs or the absence of knowledge or alternative resources. Consequently, both public and private entities are encouraged to educate people about the available exercise activities and resources for these extremely-limiting conditions.

Another aim of this study was to explore the relationship between anxiety, coping strategies and styles and levels of physical activity, as well as the impact of coping skills and exercise on participants' manifestations of anxiety. As predicted (specific hypothesis 2.1 ), a number of coping strategies correlated with anxiety symptoms in the expected direction (i.e., more functional strategies—inverse association; maladaptive strategies-direct association). Similarly, two of the coping styles, the active and the avoidant methods, were also associated in the expected way with the manifestations of anxiety. Both methods accurately represent the use of functional (active method) and dysfunctional (avoidant method) coping, so these results are similar to those found in the reviewed literature $[19,28,31]$.

Regarding physical activity, we found a relationship between exercise and the use of three functional coping strategies, namely Planning, Problem solving and Personal development, and an Active coping style (specific hypothesis 4.1). All of these associations may be indicating that people have used exercise during the pandemic along with other coping resources as a way to manage their mental and emotional states. These results highlight the importance of exercise as a coping strategy itself, and probably as a resource that is feeding from, and feeds, other adaptive coping strategies, since the use of functional coping strategies is related to a higher level of physical activity. Our results are similar to those found in several investigations [64-69]. Some other findings in the present research also support the coping role of exercise.

Specifically, we further compared the resources for coping with mental distress of the participants by their levels of physical activity during the COVID-19 pandemic. The results indicated differences between the sedentary and the active participants for Active method, and for Planning, Problem solving, Personal development and Acceptance strategies. In all cases, active participants scored higher than their sedentary counterparts (specific 
hypothesis 4.3). However, it is important to highlight that all the exercise-level groups more commonly used functional rather than maladaptive strategies to cope with distress. Even so, it should be noted that those participants who practiced higher levels of physical activity reached the highest scores. Yet most of the participants were physically active before the pandemic $(\approx 80 \%)$ and thus may have internalized the association between coping strategies and physical activity as a protective measure for the management of mental distress, it is alarming the abandonment of such positive action in moments when it is more necessary. Following this rationale, it could be expected that previously active participants who are currently sedentary could stop using functional or more effective coping strategies, or start using more dysfunctional ones if the restrictions derived from COVID-19 are prolonged in time. Our results are also congruent with previous research where it is observed that a sedentary lifestyle can be associated to an increase in negative affect and emotional symptoms during the pandemic [48-50,64-68], as well as to the worsening of other healthy behaviors and of coping with distress [46,51]. In addition, the protective effect of previous practice of exercise has also been supported $[59,60]$. Perhaps, the mere fact of practicing exercise regularly (regardless of its features, such as intensity) makes the person resort to functional strategies based on his/her personal experience, giving this to exercise a differentiating role when it comes to knowing which coping strategies to choose [69].

Moreover, we also confirmed the combined impact of coping strategies and exercise on anxiety experiences. We found that an Active method inversely predicted participants' anxiety manifestations, whereas an Avoidant method positively predicted it (specific hypothesis 2.2), but contrary to expectations (specific hypotheses 4.2 and 4.4), exercise during the pandemic was found to positively predict anxiety levels. The findings for exercise might seem counterintuitive, because it was expected an inverse association between exercise and anxiety, supporting the anxiolytic effect of physical activity [81-83]. Far from an apparent anxiety-induced effect of exercise, it is possible however that this pattern of association, along with the remaining of our findings as a whole, may be indicating that exercise is being used as a management strategy to struggle with distress and anxiety symptoms when they are experienced by the person (hypothesis 4). Supporting this, we found that regular exercise habit, anxiety levels and an Active coping style significantly predicted exercise levels, suggesting that physical activity is a coping strategy for dealing with emotional stress along with other active coping skills.

Complementarily, it is possible that the decrease in physical activity during the pandemic in previously regular practitioners induces higher levels of anxiety as a result of withdrawal, i.e., abstinence effect, as indicated by some studies and reviews $[84,85]$ and recent reviews on studies carried out during the COVID-19 pandemic [86]. This is also congruent with all the research that positively associates lower levels of exercise and a sedentary lifestyle with higher levels of anxiety $[87,88]$. These findings reaffirm the beneficial impact of active, functional coping strategies on anxiety and the benefits of exercise on people's mental health, as indicated in previous research [64-68].

Besides its contributions, this study has some limitations that deserve to be noted. The main limitation is the size and composition of the sample, with an overrepresentation of individuals who are female, in their young adulthood, highly educated and employed, making it necessary to confirm our results with larger and more heterogeneous, representative samples. Second, we have only considered total time of weekly practice to differentiate levels of active behavior, while many other parameters have been ignored (e.g., type, intensity or frequency of physical activity). Future research should include these characteristics as well as other aspects regarding reasons to practice and motives of habit changes. Additionally, it would be necessary to continue researching on the relationship between coping skills and exercise practice for managing psychological distress. All of this could help professionals to design and implement intervention programs tailored to the needs and expectations of the recipients. Only by knowing the association of coping skills with physical activity and their benefits, interventions can be developed that help people feel 
better and to cope more effectively with stressful events and distress. Finally, we have not taken into account the possible impact of some sociodemographic variables such as socioeconomic status, family composition, home conditions, etc. or even the personal experience with the COVID-19 disease. The empirical evidence indicates that their influence should be taken into account, and future investigation should be more rigorous when it comes to knowing the influence of these conditions as moderators or for controlling their effect as covariates. For the same reason, possible cultural influences should be explored. Therefore, to guarantee the generalizability of our findings beyond these limitations, research must be carried out in other nations and cultures and with citizens of different ethnicities.

Despite these limitations, our results highlight the convenience of addressing the implementation of functional coping strategies together with physical activity for promoting good mental health and alleviating mental distress. Our results also have important practical applications for program developers based on the importance of implementing adequate coping strategies, including active behavior, to minimize the possible harmful psychological effects (e.g., anxiety, stress, depression) produced by the pandemic and its consequences. Physical activity reduction or elimination in our daily routine can have negative effects, given the helpful effects of exercising, even at low levels $[80,89,90]$. Therefore, we highlight the need to implement interventions aimed at emphasizing the acquisition of functional coping strategies and training different exercise practices at home or outdoor in the general population, and particularly in people at risk or showing emotional symptoms, to promote mental health and prevent possible psychosocial difficulties during the times of a pandemic.

\section{Conclusions}

With a prevalence of anxiety symptoms of mild to severe intensity observed in $>1 / 3$ of the participants, functional coping strategies and active management styles are revealed as the most helpful for dealing with the emotional burden of the pandemic and its social and personal consequences. These coping skills are related also to a higher use of exercise as a coping strategy. We observed that regular exercisers used more frequently active coping and that exercise was associated with other forms of active, functional coping. In general, our findings supported that exercise was used as a coping strategy for dealing with emotional distress. Our results highlight the positive impact of the use of functional coping styles and of exercise practice for the management of negative states such as anxiety during the pandemic. They also underline the importance of developing interventions aimed at reducing emotional distress and optimizing physical and mental well-being of the population by means of promoting varied coping resources and decreasing the withdrawal from an active lifestyle.

Author Contributions: Conceptualization, R.L., A.O.-B. and D.G.-I.; methodology, R.L., A.O.-B. and D.G.-I.; validation, R.L., A.O.-B. and D.G.-I.; formal analysis, R.L., A.O.-B. and D.G.-I.; investigation, R.L., M.F.-D., S.Z.-C., M.A.O.-C., M.J.-T., M.D.O.-C., A.O.-B. and D.G.-I.; resources, R.L., M.F.-D., S.Z.C., M.A.O.-C., M.J.-T., M.D.O.-C., A.O.-B. and D.G.-I.; data curation, R.L., M.F.-D., S.Z.-C., M.A.O.-C., M.J.-T., M.D.O.-C., A.O.-B. and D.G.-I.; writing-original draft preparation, R.L., A.O.-B. and D.G.-I.; writing-review and editing, R.L., A.O.-B. and D.G.-I.; supervision, R.L., M.F.-D. and D.G.-I.; project administration, M.F.-D. and S.Z.-C.; funding acquisition, M.F.-D., S.Z.-C. and D.G.-I. All authors have read and agreed to the published version of the manuscript.

Funding: This research was funded by the financial aid conceded to the Research project "Impacto psicológico y afrontamiento del Covid-19 en personal sanitario de países hispanohablantes" (Impacto psicológico y afrontamiento del Covid-19 en población general) INV2871 by Universidad Cooperativa de Colombia. Grupo de Investigación Estudios Sociales Interdisciplinares COD: COL0082654.

Institutional Review Board Statement: The study was conducted according to the guidelines of the Declaration of Helsinki, and approved by the Comité Bioético-University Cooperative of Colombia $(14 / 08 / 2020)$. 
Informed Consent Statement: Informed consent was obtained from all subjects involved in the study.

Acknowledgments: We are grateful to all participants who collaborated in this study and Universidad Cooperativa de Colombia.

Conflicts of Interest: The authors declare no conflict of interest.

\section{References}

1. World Health Organization. Rolling Updates on Coronavirus Disease (COVID-19). Available online: https://www.who.int/ emergencies/diseases/novel-coronavirus-2019/events-as-they-happen (accessed on 15 March 2021).

2. Hellewell, J.; Abbott, S.; Gimma, A.; Bosse, N.I.; Jarvis, C.I.; Russell, T.W.; Munday, J.D.; Kucharski, A.J.; Edmunds, W.J.; Funk, S.; et al. Feasibility of controlling COVID-19 outbreaks by isolation of cases and contacts. Lancet Glob. Health 2020, 8, e488-e496. [CrossRef]

3. Ranaei, V.; Pilevar, Z.; Aghamolaei, T. Behavioral reactions and psychological responses to 2019-ncov: A narrative review. Iran. J. Psychiatry Behav. Sci. 2020, 14, e104727. [CrossRef]

4. Cénat, J.M.; Blais-Rochette, C.; Kokou-Kpolou, C.K.; Noorishad, P.G.; Mukunzi, J.N.; McIntee, S.E.; Dalexis, R.D.; Goulet, M.A.; Labelle, P.R. Prevalence of symptoms of depression, anxiety, insomnia, posttraumatic stress disorder, and psychological distress among populations affected by the COVID-19 pandemic: A systematic review and meta-analysis. Psychiatry Res. 2021, 295, 113599. [CrossRef]

5. López-Bueno, R.; Calatayud, J.; Casaña, J.; Casajús, J.A.; Smith, L.; Tully, M.A.; Andersen, L.L.; López-Sánchez, G.F. COVID-19 Confinement and health risk behaviors in Spain. Front. Psychol. 2020, 11, 1426. [CrossRef] [PubMed]

6. Shigemura, J.; Ursano, R.J.; Morganstein, J.C.; Kurosawa, M.; Benedek, D.M. Public responses to the novel 2019 coronavirus (2019-nCoV) in Japan: Mental health consequences and target populations. Psychiatry Clin. Neurosci. 2020, 74, 281-282. [CrossRef]

7. Xiang, Y.T.; Yang, Y.; Li, W.; Zhang, L.; Zhang, Q.; Cheung, T.; Ng, C.H. Timely mental health care for the 2019 novel coronavirus outbreak is urgently needed. Lancet Psychic. 2020, 7, 228-229. [CrossRef]

8. Brooks, S.K.; Webster, R.K.; Smith, L.E.; Woodland, L.; Wessely, S.; Greenberg, N.; Rubin, G.J. The psychological impact of quarantine and how to reduce it: Rapid review of the evidence. Lancet 2020, 395, 912-920. [CrossRef]

9. Mukhtar, S. Psychological health during the coronavirus disease 2019 pandemic outbreak. Int. J. Soc. Psychiatry 2020, 66, 512-516. [CrossRef]

10. Fiorillo, A.; Gorwood, P. The consequences of the COVID-19 pandemic on mental health and implications for clinical practice. Eur. Psychic. 2020, 63, e32. [CrossRef]

11. Chandu, V.C.; Marella, Y.; Panga, G.S.; Pachava, S.; Vadapalli, V. Measuring the impact of COVID-19 on mental health: A scoping review of the existing scales. Indian J. Psychol. Med. 2020, 42, 421-427. [CrossRef] [PubMed]

12. Clemente-Suárez, V.J.; Dalamitros, A.A.; Beltran-Velasco, A.I.; Mielgo-Ayuso, J.; Tornero-Aguilera, J.F. Social and psychophysiological consequences of the COVID-19 pandemic: An extensive literature review. Front. Psychol. 2020, 11, 580225. [CrossRef] [PubMed]

13. Wu, T.; Jia, X.; Shi, H.; Niu, J.; Yin, X.; Xie, J.; Wang, X. Prevalence of mental health problems during the COVID-19 pandemic: A systematic review and meta-analysis. J. Affect. Disord. 2021, 281, 91-98. [CrossRef] [PubMed]

14. Zurcher, S.J. Prevalence of mental health problems during virus epidemics in the general public, health care workers and survivors: A rapid review of the evidence. Public Health Front. 2020, 8, 560389. [CrossRef] [PubMed]

15. Prati, G.; Mancini, A.D. The psychological impact of COVID-19 pandemic lockdowns: A review and meta-analysis of longitudinal studies and natural experiments. Psychol. Med. 2021, 51, 201-211. [CrossRef]

16. Salari, N.; Hosseinian-Far, A.; Jalali, R.; Vaisi-Raygani, A.; Rasoulpoor, S.; Mohammadi, M.; Rasoulpoor, S.; Khaledi-Paveh, B. Prevalence of stress, anxiety, depression among the general population during the COVID-19 pandemic: A systematic review and meta-analysis. Glob. Health 2020, 16, 57. [CrossRef]

17. Cavicchioli, M.; Ferrucci, R.; Guidetti, M.; Canevini, M.P.; Pravettoni, G.; Galli, F. What will be the impact of the covid-19 quarantine on psychological distress? Considerations based on a systematic review of pandemic outbreaks. Healthcare 2021, 9 , 101. [CrossRef]

18. Li, W.; Yang, Y.; Liu, Z.H.; Zhao, Y.J.; Zhang, Q.; Zhang, L.; Cheung, T.; Xiang, Y.T. Progression of mental health services during the COVID-19 outbreak in China. Int. J. Biol. Sci. 2020, 16, 1732-1738. [CrossRef]

19. Chew, Q.H.; Wei, K.C.; Vasoo, S.; Chua, H.C.; Sim, K. Narrative synthesis of psychological and coping responses towards emerging infectious disease outbreaks in the general population: Practical considerations for the COVID-19 pandemic. SMJ 2020, 61, 350-356. [CrossRef]

20. Shamblaw, A.L.; Rumas, R.L.; Best, M.W. Coping during the COVID-19 pandemic: Relations with mental health and quality of life. Can. Psychol. 2021, 62, 92-100. [CrossRef]

21. Bonanno, G.A.; Westphal, M.; Mancini, A.D. Resilience to loss and potential trauma. Annu. Rev. Clin. Psychol. 2011, 7, 511-535. [CrossRef] 
22. Fredrickson, B.L.; Tugade, M.M.; Waugh, C.E.; Larkin, G.R. What good are positive emotions in crises? A prospective study of resilience and emotions following the terrorist attacks on the United States on September 11th, 2001. J. Pers. Soc. Psychol. 2003, 84, 365-376. [CrossRef]

23. Budimir, S.; Probst, T.; Pieh, C. Coping strategies and mental health during COVID-19 lockdown. J. Ment. Health 2021, $30,156-163$. [CrossRef] [PubMed]

24. Cheng, C.; Wang, H.Y.; Ebrahimi, O.V. Adjustment to a "new normal:" Coping flexibility and mental health issues during the COVID-19 Pandemic. Front. Psychiat. 2021, 12, 353. [CrossRef] [PubMed]

25. Dewa, L.H.; Crandell, C.; Choong, E.; Jaques, J.; Bottle, A.; Kilkenny, C.; Aylin, P.C.Y. Cope a mixed-methods coproduced study on the mental health status and coping strategies of young people during COVID-19 UK lockdown. J. Adoles. Health 2021, 68, 666-675. [CrossRef]

26. Fluharty, M.; Bu, F.; Steptoe, A.; Fancourt, D. Coping strategies and mental health trajectories during the first 21 weeks of COVID-19 lockdown in the United Kingdom. Soc. Sci. Med. 2021, 279, 113958. [CrossRef] [PubMed]

27. Humphrey, A.; Vari, O. Meaning Matters: The impact of Self-Perceived Meaning in Life and its predictors on Psychological Stressors associated with the COVID-19 Pandemic. Behav. Sci. 2021, 11, 50. [CrossRef]

28. Kunzler, A.M.; Stoffers-Winterling, J.; Stoll, M.; Mancini, A.L.; Lehmann, S.; Blessin, M.; Gilan, D.; Helmreich, I.; Hufert, F.; Lieb, K. Mental health and psychosocial support strategies in highly contagious emerging disease outbreaks of substantial public concern: A systematic scoping review. PLoS ONE 2021, 16, e0244748. [CrossRef]

29. Nitschke, J.P.; Forbes, P.A.G.; Ali, N.; Cutler, J.; Apps, M.A.J.; Lockwood, P.L.; Lamm, C. Resilience during uncertainty? Greater social connectedness during COVID-19 lockdown is associated with reduced distress and fatigue. Br. J. Health Psychol. 2021, 26, 553-569. [CrossRef]

30. Patias, N.D.; Von Hohendorff, J.; Cozzer, A.J.; Flores, P.A.; Scorsolini-Comin, F. Mental health and coping strategies in undergraduate and graduate students during COVID-19 pandemic. Trends Psychol. 2021, 1-20. [CrossRef]

31. Almeda, N.; García-Alonso, C.; Salvador-Carulla, L. Mental health planning at a very early stage of the COVID-19 crisis: A systematic review of online international strategies and recommendations. BMC Psychiatry 2021, 21, 43. [CrossRef]

32. Cunningham, C.; O'Sullivan, R.; Caserotti, P.; Tully, M.A. Consequences of physical inactivity in older adults: A systematic review of reviews and meta-analyses. Scand. J. Med. Sci. Spor. 2020, 30, 816-827. [CrossRef]

33. Gallè, F.; Sabella, E.A.; Da Molin, G.; De Giglio, O.; Caggiano, G.; Di Onofrio, V.; Ferracuti, S.; Montagna, M.T.; Liguori, G.; Orsi, G.B.; et al. Understanding knowledge and behaviors related to CoViD-19 epidemic in Italian undergraduate students: The EPICO Study. Int. J. Environ. Res. Public Health 2020, 17, 3481. [CrossRef]

34. Hossain, M.; Sultana, A.; Purohit, N. Mental health outcomes of quarantine and isolation for infection prevention: A systematic umbrella review of the global evidence. Epidemiol. Health 2020. [CrossRef] [PubMed]

35. Stockwell, S.; Trott, M.; Tully, M.; Shin, J.; Barnett, Y.; Butler, L.; Mcdermott, D.; Schuch, F.; Smith, L. Changes in physical activity and sedentary behaviours from before to during the COVID-19 pandemic lockdown: A systematic review. BMJ Open Sport Exerc. Med. 2021, 7, e000960. [CrossRef] [PubMed]

36. Bowes, A.; Lomax, L.; Piasecki, J. The impact of the COVID-19 lockdown on elite sportswomen. Manag. Sport Leis. 2020, 48, 1-17. [CrossRef]

37. Cancello, R.; Soranna, D.; Zambra, G.; Zambon, A.; Invitti, C. Determinants of the lifestyle changes during COVID-19 pandemic in the residents of Northern Italy. Int. J. Environ. Res. Public Health 2020, 17, 6287. [CrossRef] [PubMed]

38. Constandt, B.; Thibaut, E.; De Bosscher, V.; Scheerder, J.; Ricour, M.; Willem, A. Exercising in times of lockdown: An analysis of the impact of COVID-19 on levels and patterns of exercise among adults in Belgium. Int. J. Environ. Res. Public Health 2020, 17, 4144. [CrossRef] [PubMed]

39. Karuc, J.; Sorić, M.; Radman, I.; Mišigoj-Duraković, M. Moderators of change in physical activity levels during restrictions due to COVID-19 Pandemic in young urban adults. Sustainability 2020, 12, 6392. [CrossRef]

40. Mandelkorn, U.; Genzer, S.; Choshen-Hillel, S.; Reiter, J.; Meira, E.; Cruz, M.; Hochner, H.; Kheirandish-Gozal, L.; Gozal, D.; Gileles-Hillel, A. Escalation of sleep disturbances amid the COVID-19 pandemic: A cross-sectional international study. J. Clin. Sleep Med. 2021, 17, 45-53. [CrossRef] [PubMed]

41. Wang, X.; Lei, S.M.; Le, S.; Yang, Y.; Zhang, B.; Yao, W.; Gao, Z.; Cheng, S. Bidirectional Influence of the COVID-19 pandemic lockdowns on health behaviors and quality of life among Chinese adults. Int. J. Environ. Res. Public Health 2020, $17,5575$. [CrossRef]

42. Caputo, E.L.; Reichert, F.F. Studies of physical activity and COVID-19 during the pandemic: A scoping review. J. Phys. Act. Health 2020, 17, 1275-1284. [CrossRef]

43. Cheval, B.; Sivaramakrishnan, H.; Maltagliati, S.; Fessler, L.; Forestier, C.; Sarrazin, P.; Orsholits, D.; Chalabaev, A.; Sander, D.; Ntoumanis, N.; et al. Relationships between changes in self-reported physical activity, sedentary behaviour and health during the coronavirus (COVID-19) pandemic in France and Switzerland. J. Sports Sci. 2021, 39, 699-704. [CrossRef] [PubMed]

44. Faulkner, J.; O’Brien, W.J.; McGrane, B.; Wadsworth, D.; Batten, J.; Askew, C.D.; Badenhorst, C.; Byrd, E.; Coulter, M.; Draper, N.; et al. Physical activity, mental health and well-being of adults during initial COVID-19 containment strategies: A multi-country cross-sectional analysis. J. Sci. Med. Sport 2021, 24, 320-326. [CrossRef] [PubMed] 
45. Meyer, J.; McDowell, C.; Lansing, J.; Brower, C.; Smith, L.; Tully, M.; Herring, M. Changes in physical activity and sedentary behavior in response to COVID-19 and their associations with mental health in 3052 US adults. Int. J. Environ. Res. Public Health 2020, 17, 6469. [CrossRef] [PubMed]

46. Werneck, A.O.; Silva, D.R.; Malta, D.C.; Lima, M.G.; Souza-Júnior, P.; Azevedo, L.O.; Barros, M.; Szwarcwald, C.L. The mediation role of sleep quality in the association between the incidence of unhealthy movement behaviors during the COVID-19 quarantine and mental health. Sleep Med. 2020, 76, 10-15. [CrossRef]

47. Werneck, A.O.; Silva, D.R.; Malta, D.C.; Souza-Júnior, P.; Azevedo, L.O.; Barros, M.; Szwarcwald, C.L. Physical inactivity and elevated TV-viewing reported changes during the COVID-19 pandemic are associated with mental health: A survey with 43,995 Brazilian adults. J. Psychosom. Res. 2021, 140, 110292. [CrossRef]

48. Di Corrado, D.; Magnano, P.; Muzii, B.; Coco, M.; Guarnera, M.; De Lucia, S.; Maldonato, N.M. Effects of social distancing on psychological state and physical activity routines during the COVID-19 pandemic. Sport Sci. Health 2020. [CrossRef] [PubMed]

49. Gismero-González, E.; Bermejo-Toro, L.; Cagigal, V.; Roldán, A.; Martínez-Beltrán, M.J.; Halty, L. Emotional impact of COVID-19 lockdown among the Spanish population. Front. Psychol. 2020, 11, 616978. [CrossRef] [PubMed]

50. Ruiz, M.C.; Devonport, T.J.; Chen-Wilson, C.J.; Nicholls, W.; Cagas, J.Y.; Fernandez-Montalvo, J.; Choi, Y.; Robazza, C. A cross-cultural exploratory study of health behaviors and wellbeing during COVID-19. Front. Psychol. 2021, 11, 608216. [CrossRef]

51. Naughton, F.; Ward, E.; Khondoker, M.; Belderson, P.; Marie Minihane, A.; Dainty, J.; Hanson, S.; Holland, R.; Brown, T.; Notley, C. Health behaviour change during the UK COVID-19 lockdown: Findings from the first wave of the C-19 health behaviour and well-being daily tracker study. Br. J. Health Psychol. 2021. [CrossRef]

52. Ginoux, C.; Isoard-Gautheur, S.; Teran-Escobar, C.; Forestier, C.; Chalabaev, A.; Clavel, A.; Sarrazin, P. Being active during the lockdown: The recovery potential of physical activity for well-being. Int. J. Environ. Res. Public Health 2021, 18, 1707. [CrossRef]

53. Meira, C.M., Jr.; Meneguelli, K.S.; Leopoldo, M.; Florindo, A.A. Anxiety and leisure-domain physical activity frequency, duration, and intensity during COVID-19 pandemic. Front. Psychol. 2020, 11, 603770. [CrossRef] [PubMed]

54. Sang, X.; Menhas, R.; Saqib, Z.A.; Mahmood, S.; Weng, Y.; Khurshid, S.; Iqbal, W.; Shahzad, B. The psychological impacts of COVID-19 home confinement and physical activity: A structural equation model analysis. Front. Psychol. 2021, 11, 614770. [CrossRef]

55. Silva Moreira, P.; Ferreira, S.; Couto, B.; Machado-Sousa, M.; Fernández, M.; Raposo-Lima, C.; Sousa, N.; Picó-Pérez, M.; Morgado, P. Protective elements of mental health status during the COVID-19 outbreak in the Portuguese population. Int. J. Environ. Res. Public Health 2021, 18, 1910. [CrossRef]

56. Nienhuis, C.P.; Lesser, I.A. The impact of COVID-19 on women's physical activity behavior and mental well-being. Int. J. Environ. Res. Public Health 2020, 17, 9036. [CrossRef] [PubMed]

57. Robinson, E.; Boyland, E.; Chisholm, A.; Harrold, J.; Maloney, N.G.; Marty, L.; Mead, B.R.; Noonan, R.; Hardman, C.A. Obesity, eating behavior and physical activity during COVID-19 lockdown: A study of UK adults. Appetite 2021, 156, 104853. [CrossRef]

58. Stieger, S.; Lewetz, D.; Swami, V. Emotional well-being under conditions of lockdown: An experience sampling study in Austria during the COVID-19 pandemic. J. Happiness Stud. 2021, 1-18. [CrossRef]

59. Amit Aharon, A.; Dubovi, I.; Ruban, A. Differences in mental health and health-related quality of life between the Israeli and Italian population during a COVID-19 quarantine. Qual. Life Res. 2021. [CrossRef]

60. Weaver, R.H.; Jackson, A.; Lanigan, J.; Power, T.G.; Anderson, A.; Cox, A.E.; Eddy, L.; Parker, L.; Sano, Y.; Weybright, E. Health behaviors at the onset of the COVID-19 pandemic. Am. J. Health Behav. 2021, 45, 44-61. [CrossRef] [PubMed]

61. Antunes, R.; Frontini, R. Physical activity and mental health in COVID-19 times: An editorial. Sleep Med. 2021, 77, 295-296. [CrossRef]

62. Puyat, J.H.; Ahmad, H.; Avina-Galindo, A.M.; Kazanjian, A.; Gupta, A.; Ellis, U.; Ashe, M.C.; Vila-Rodriguez, F.; Halli, P.; Salmon, A.; et al. A rapid review of home-based activities that can promote mental wellness during the COVID-19 pandemic. PLoS ONE 2020, 15, e0243125. [CrossRef]

63. Violant-Holz, V.; Gallego-Jiménez, M.G.; González-González, C.S.; Muñoz-Violant, S.; Rodríguez, M.J.; Sansano-Nadal, O.; Guerra-Balic, M. Psychological health and physical activity levels during the COVID-19 Pandemic: A systematic review. Int. J. Environ. Res. Public Health 2020, 17, 9419. [CrossRef]

64. Fernandez-Rio, J.; Cecchini, J.A.; Mendez-Gimenez, A.; Carriedo, A. Mental well-being profiles and physical activity in times of social isolation by the COVID-19: A latent class analysis. J. Sport Exerc. Psychol. 2021. [CrossRef]

65. Khan, A.A.; Lodhi, F.S.; Rabbani, U.; Ahmed, Z.; Abrar, S.; Arshad, S.; Irum, S.; Khan, M.I. Impact of coronavirus disease (COVID-19) pandemic on psychological well-being of the Pakistani general population. Front. Psychiatry 2021, 11, 564364. [CrossRef]

66. Lyons, Z.; Wilcox, H.; Leung, L.; Dearsley, O. COVID-19 and the mental well-being of Australian medical students: Impact, concerns and coping strategies used. Australas. Psychiatry 2020, 28, 649-652. [CrossRef] [PubMed]

67. Martínez, M.; Luis, E.O.; Oliveros, E.Y.; Fernández-Berrocal, P.; Sarrionandia, A.; Vidaurreta, M.; Bermejo-Martins, E. Validity and reliability of the Self-Care Activities Screening Scale (SASS-14) during COVID-19 lockdown. Health Qual. Life Outcomes 2021, 19, 1. [CrossRef] [PubMed]

68. Solé, B.; Verdolini, N.; Amoretti, S.; Montejo, L.; Rosa, A.R.; Hogg, B.; Garcia-Rizo, C.; Mezquida, G.; Bernardo, M.; Martinez-Aran, A.; et al. Effects of the COVID-19 pandemic and lockdown in Spain: Comparison between community controls and patients with a psychiatric disorder. Preliminary results from the BRIS-MHC STUDY. J. Affect. Disord. 2021, 281, 13-23. [CrossRef] 
69. Shechter, A.; Diaz, F.; Moise, N.; Anstey, D.E.; Ye, S.; Agarwal, S.; Birk, J.L.; Brodie, D.; Cannone, D.E.; Chang, B.; et al. Psychological distress, coping behaviors, and preferences for support among New York healthcare workers during the COVID-19 pandemic. Gen. Hosp. Psychiatry 2020, 66, 1-8. [CrossRef]

70. Sallis, J.F.; Adlakha, D.; Oyeyemi, A.; Salvo, D. An international physical activity and public health research agenda to inform coronavirus disease-2019 policies and practices. J. Sport Health Sci. 2020, 9, 328-334. [CrossRef] [PubMed]

71. Hulley, S.B.; Cummings, S.R.; Browner, W.S.; Grady, D.; Newman, T.B. Designing Clinical Research: An Epidemiologic Approach, 4th ed.; Lippincott Williams \& Wilkins: Philadelphia, PA, USA, 2013; Appendix 6C; p. 79.

72. Lusilla, M.P.; Sánchez, A.; Sanz, C.; López, J. Validación estructural de la escala heteroevaluada de ansiedad de Zung. An. Psicol. $1990,6,39$.

73. Tanaka-Matsumi, J.; Kameoka, V.A. Reliabilities and concurrent validities of popular self-report measures of depression, anxiety, and social desirability. J. Consult. Clin. Psychol. 1986, 54, 328. [CrossRef] [PubMed]

74. Dunstan, D.A.; Scott, N. Norms for Zung's Self-rating Anxiety Scale. BMC Psychiatry 2020, 20, 90. [CrossRef]

75. Zhang, Y.; Kong, D.; Li, S.; Yang, N. The effects of social support on sleep quality of medical staff treating patients with coronavirus disease 2019 (COVID-19) in 34699 January and February 2020 in China. Med. Sci. Monit. 2020, 26, e923549.

76. Xiao, H.; Zhang, Y.; Kong, D.; Li, S.; Yang, N. Social capital and sleep quality in individuals who self-isolated for 14 days during the coronavirus disease 2019 (covid-19) outbreak in January 2020 in China. Med. Sci. Monit. 2020, 26, e923921. [CrossRef]

77. Herrera-Espiñeira, C.; del Aguila, M.D.M.R.; del Castillo, M.R.; Valdivia, A.F.; Sánchez, I.R. Relationship between anxiety level of patients and their satisfaction with different aspects of healthcare. Health Policy 2009, 89, 37-45. [CrossRef]

78. Fernández-Abascal, E.G. Estilos y estrategias de afrontamiento. In Cuaderno de Prácticas de Motivación y Emoción; FernándezAbascal, E.G., Palmero, F., Chóliz, M., Martínez, F., Eds.; Pirámide: Madrid, Spain, 1997.

79. Martín, M.J.; Jiménez, M.P.; Fernández Abascal, E. Estudio sobre la escala de estilos y estrategias de afrontamiento (E3A). REME $1997,3,1$.

80. Stubbs, B.; Koyanagi, A.; Hallgren, M.; Firth, J.; Richards, J.; Schuch, F.; Rosenbaum, S.; Mugisha, J.; Veronese, N.; Lahti, J.; et al. Physical activity and anxiety: A perspective from the World Health Survey. J. Affect. Disord. 2017, 208, 545-552. [CrossRef] [PubMed]

81. Aylett, E.; Small, N.; Bower, P. Exercise in the treatment of clinical anxiety in general practice- a systematic review and metaanalysis. BMC Health Serv. Res. 2018, 18, 559. [CrossRef]

82. McDowell, C.P.; Dishman, R.K.; Gordon, B.R.; Herring, M.P. Physical activity and anxiety: A systematic review and meta-analysis of prospective cohort studies. Am. J. Prev. Med. 2019, 57, 545-556. [CrossRef] [PubMed]

83. Schuch, F.B.; Stubbs, B.; Meyer, J.; Heissel, A.; Zech, P.; Vancampfort, D.; Hiles, S.A. Physical activity protects from incident anxiety: A meta-analysis of prospective cohort studies. Depress. Anxiety 2019, 36, 846-858. [CrossRef] [PubMed]

84. Edwards, M.K.; Loprinzi, P.D. Experimentally increasing sedentary behavior results in increased anxiety in an active young adult population. J. Affect. Disord. 2016, 204, 166-173. [CrossRef]

85. Weinstein, A.A.; Koehmstedt, C.; Kop, W.J. Mental health consequences of exercise withdrawal: A systematic review. Gen. Hosp. Psychiatry 2017, 49, 11-18. [CrossRef] [PubMed]

86. Wolf, S.; Zeibig, J.; Seiffer, B.; Welkerling, J.; Brokmeier, L.; Atrott, B.; Ehring, T.; Schuch, F.B. Can physical activity protect against depression and anxiety during the COVID-19 pandemic? A rapid systematic review. Res. Sq. 2020. Preprint PPR218366. [CrossRef]

87. Allen, M.S.; Walter, E.E.; Swann, C. Sedentary behaviour and risk of anxiety: A systematic review and meta-analysis. J. Affect. Disord. 2019, 242, 5-13. [CrossRef] [PubMed]

88. Stanczykiewicz, B.; Banik, A.; Knoll, N.; Keller, J.; Hohl, D.H.; Rosińczuk, J.; Luszczynska, A. Sedentary behaviors and anxiety among children, adolescents and adults: A systematic review and meta-analysis. BMC Public Health 2019, 19, 459. [CrossRef] [PubMed]

89. Ensari, I.; Greenlee, T.A.; Motl, R.W.; Petruzzello, S.J. Meta-analysis of acute exercise effects on state anxiety: An update of randomized controlled trials over the past 25 years. Depress. Anxiety 2015, 32, 624-634. [CrossRef]

90. Stubbs, B.; Vancampfort, D.; Rosenbaum, S.; Firth, J.; Cosco, T.; Veronese, N.; Salum, G.A.; Schuch, F.B. An examination of the anxiolytic effects of exercise for people with anxiety and stress-related disorders: A meta-analysis. Psychic Res. 2017, 249, 102-108. [CrossRef] 